\title{
BMJ Open BASAN index (Body mass index, Age, Sex, Arterial hypertension and Neck circumference) predicts severe apnoea in adults living at high altitude
}

\author{
Henry Oliveros (D) , ${ }^{1}$ Rafael Lobelo, ${ }^{2}$ Luis Fernando Giraldo-Cadavid, ${ }^{1,3,4}$ \\ Alirio Bastidas, ${ }^{1}$ Constanza Ballesteros, ${ }^{2}$ Rafael Bernal, ${ }^{2}$ Lilian Patiño, ${ }^{2}$ \\ Karen Herrera, ${ }^{2}$ David Gozal ${ }^{5}$
}

To cite: Oliveros $\mathrm{H}$, Lobelo $\mathrm{R}$, Giraldo-Cadavid LF, et al. BASAN index (Body mass index, Age, Sex, Arterial hypertension and Neck circumference) predicts severe apnoea in adults living at high altitude. BMJ Open 2021;11:e044228. doi:10.1136/ bmjopen-2020-044228

- Prepublication history and additional supplemental material for this paper are available online. To view these files, please visit the journal online (http://dx.doi.org/10.1136/ bmjopen-2020-044228).

Received 27 August 2020 Accepted 11 May 2021

A) Check for updates

(c) Author(s) (or their employer(s)) 2021. Re-use permitted under CC BY-NC. No commercial re-use. See rights and permissions. Published by BMJ.

For numbered affiliations see end of article.

Correspondence to Dr Henry Oliveros; henry.oliveros@unisabana. edu.co

\section{ABSTRACT}

Objectives Obstructive sleep apnoea (OSA)/hypopnoea syndrome is associated with serious and major multiorgan morbidities, particularly in its most severe forms. However, no severe OSA screening instruments are available for high altitude residents that enable adequate identification and clinical prioritisation of such patients. We aimed at developing a severe OSA prediction tool based on the clinical characteristics and anthropometric measurements of a clinical referral cohort living at 2640 m.a.s.l. Design Cohort-nested cross-sectional study. Setting Sleep laboratory for standard polysomnography (PSG) in Colombia.

Participants A predictive model was generated from 8718 participants referred to the PSG laboratory. Results were subsequently validated in a second cohort of 1898 participants.

Primary outcome To identify clinical and anthropometric variables associated with severe OSA ( $>30$ events/hour) and to include them in a binary logistic regression model.

Results The significant variables that were retained with the presence of severe OSA included Body mass index (BMI), Age, Sex, Arterial hypertension and Neck circumference (BASAN). The area under the receiver operating characteristic curvefor the BASAN index was 0.69 (95\% Cl: 0.68 to 0.70$)$ in the derivation cohort and 0.67 (95\% Cl: 0.65 to 0.69 ) in the validation cohort, whereby a BASAN index $\geq 2$ had a sensitivity of $95 \%$ and a specificity of $17 \%$ to detect severe OSA.

Conclusion An objectively based approach to screen for the presence of severe OSA, the BASAN index, exhibits favourable sensitivity characteristics that should enable its operational use as a screening tool in a Hispanic population with a clinical suspicion of OSA and living at high altitude.

\section{INTRODUCTION}

Obstructive sleep apnoea (OSA)/hypopnoea syndrome has a very high prevalence around the world $^{1-3}$ and has been associated with significant increases in the risk of hypertension, ${ }^{4}$ coronary artery disease, ${ }^{56}$ stroke ${ }^{78}$ and sudden death. ${ }^{9}$ Furthermore, highlanders
Strengths and limitations of this study

- This study used data drawn from a large patient cohort attending a sleep laboratory at high altitude in which all patients had a polysomnography for a definitive diagnosis of obstructive sleep apnoea (OSA)/ hypopnoea syndrome.

- We described a rigorous approach to evaluate variables that are used in multiple tools for the diagnosis of OSA and identified a logistic model that uses simple variables with favourable performances for the diagnosis of this disease.

- There was a possibility of a confounding bias and omission, as with any observational study.

suffering from OSA have a higher prevalence of pulmonary hypertension, which therefore prioritises the detection of OSA in a timely fashion in high altitude residents. ${ }^{10-12}$ OSA has also been associated with a higher rate of traffic accidents, cognitive behavioural disorders and alterations in the overall quality of life. This ultimately results in an increased all-cause mortality and, as such, is considered a major public health problem. ${ }^{13}$ Standard overnight in-laboratory polysomnography (PSG) is the diagnostic test of choice for this condition, but it requires a significant resource infrastructure. Unfortunately, in most countries, a limited availability of PSGs precludes timely referrals and diagnoses for a large majority of these patients. These issues have fostered efforts aimed at developing clinical instruments that reliably predict the risk of $\mathrm{OSA}^{1415}$ and to allow for rational prioritisation of high-risk patients. Two types of instruments have gained wide implementation. The first type is based on a mix of subjective reporting by the patients and objective office-based measures and includes the Epworth Sleepiness Scale (ESS), ${ }^{16}$ the 
Berlin questionnaire, ${ }^{17}$ snoring, tiredness, observed apnoea, blood pressure (STOP) $;{ }^{18}$ STOP, body mass index (BMI), age, neck circumference, gender (STOPBang) $;{ }^{19}$ and more recently, the neck, obesity, snoring, age, sex (NoSAS).$^{2021}$ The second type is based on simplified objective screening tools (No-Apnoea) ${ }^{22-24}$

Among the most widely used instruments is the ESS. However, this tool was created to measure diurnal sleepiness and not meant as a screening tool for OSA. Not surprisingly, its performance is clearly inferior to later instruments in this regard. ${ }^{24-26}$ Other frequently used instruments are the Berlin ${ }^{14-18}$ and STOP questionnaires, which primarily rely on self-reported symptoms. The Berlin questionnaire consists of 10 items related to snoring, non-restorative sleep, drowsiness while driving, apnoeas during sleep, arterial hypertension and BMI. ${ }^{17}$ It has a sensitivity and specificity of $80 \%$ and $46 \%$, respectively, when the OSA is defined as having an apnoeahypopnoea index (AHI) $\geq 5$ events/hour. Furthermore, it has a sensitivity of $91 \%$ and specificity of $37 \%$ when OSA is defined as an AHI $\geq 15$ events/hour. ${ }^{27}$ The STOP-Bang questionnaire is an eight-item survey that incorporates information about STOP, BMI, age, neck circumference and gender. For the diagnosis of OSA, a score $\geq 5$ has a sensitivity and specificity of $85 \%$ and $53 \%$, respectively; using a threshold of AHI $>15$ events, there is a sensitivity and specificity of $91 \%$ and $40 \%$, respectively; and using a threshold of AHI $>15$ events/hour, there is a sensitivity and specificity of $95 \%$ and $35 \%$, respectively. ${ }^{18}$ Conversely, we recently reported a two-item tool that is predicated on neck circumference and age. This tool has exhibited favourable screening capabilities as evidenced by an accuracy of $78.1 \%, 68.8 \%$ and $54.4 \%$, respectively, for OSA $\geq 5$, OSA $\geq 15$ and OSA $\geq 30$ events/hour. ${ }^{22}$

Approximately $2.3 \%$ of the world's population lives between 2000 and 2500 m.a.s.l. This means that there are approximately 178 million people residing at such high altitude, with an additional 60 million people living between 2500 and 3500 m.a.s.l. (high altitude, class 3 of the mountain classification of the United Nations Environment Programme).$^{28}$ The effects of altitude on sleep have been described since the beginning of the 20th century. ${ }^{29}$ These effects include a higher frequency of periodic breathing, central sleep apnoea, increased risk of oxyhaemoglobin desaturation events during sleep, frequent awakenings and a decrease in the proportion of slow wave sleep. ${ }^{30}$ These effects become apparent in non-acclimated people at altitudes of 2000-2500 m.a.s.1. ${ }^{28}{ }^{30-32}$ Although these effects are mitigated with acclimatisation, ${ }^{33} 34$ an implementation of the aforementioned screening instruments may be underperforming. Thus, they may require the development of better tailored tools for sleep apnoea screening that are specifically designed for these populations and in whom the prevalence of respiratory disorders during sleep may be higher than at sea level. Our aim in this study was to develop a simple screening tool that enables the reliable detection of patients with severe OSA who are living at 2640 m.a.s.l. Moreover, this tool would be based on objectively assessed clinical characteristics and anthropometric measurements.

\section{METHODS}

This was a cross-sectional study nested in a cohort of a sleep laboratory in the city of Bogotá, Colombia. Included in this study were adult patients (age $>18$ years) referred for a standard polysomnographic study due to a clinical suspicion of OSA and living in Bogotá, a city at 2640 m.a.s.l. Exclusion criteria were patients treated surgically (correction of the upper airways) or medically (continuous positive airway pressure or bilevel positive airway pressure) for OSA. Other exclusion criteria included craniofacial

Table 1 General characteristics of the cohort

\begin{tabular}{|c|c|c|c|c|c|c|}
\hline Characteristics & ALL & $\mathrm{AHI}<5$ & AHI 5-14 & AHI 15-29 & $\mathrm{AHI} \geq \mathbf{3 0}$ & $P$ value \\
\hline Number (\%) & 8.580 & $449(5.2)$ & $1638(18.9)$ & $2280(26.5)$ & 4233 (49.2) & \\
\hline Sex (male), n (\%) & $4250(49.5)$ & $137(30.5)$ & $633(38.9)$ & $1046(45.9)$ & $2434(57.6)$ & $0.0001^{*}$ \\
\hline BMI $\left(\mathrm{kg} / \mathrm{m}^{2}\right)$ mean (SD) & $30.1(6.3)$ & $27.3(5.8)$ & $28.3(5.8)$ & $29.4(5.9)$ & $31.4(6.4)$ & $0.0001 \dagger$ \\
\hline Neck circumference $(\mathrm{cm})$ mean (SD) & $38.6(4.2)$ & $36.1(3.8)$ & $37.1(3.9)$ & $38(4)$ & $39.8(4.3)$ & $0.0001 \dagger$ \\
\hline Snoring n (\%) & $6423(77.6)$ & $320(74.5)$ & $1162(74.5)$ & $1668(75.9)$ & $3273(80.1)$ & $0.49^{*}$ \\
\hline Witnessed stop breathing $\mathrm{n}(\%)$ & $5510(67)$ & $257(60.3)$ & $1010(64.7)$ & $1458(66.5)$ & $2785(68.8)$ & $0.007^{\star}$ \\
\hline Awakening n (\%) & $6946(82)$ & $358(80.8)$ & $1291(79.7)$ & $1815(80.2)$ & $3482(83.3)$ & $0.06^{*}$ \\
\hline Sleepy in day $n(\%)$ & $5673(66.7)$ & $293(66.1)$ & $1038(64.1)$ & $1477(65.3)$ & 2865 (68.5) & $0.001^{*}$ \\
\hline Drowning $\mathrm{n}(\%)$ & $5625(66.2)$ & $294(66.5)$ & 1059 (65.6) & 1499 (66.3) & $2773(66.3)$ & $0.960^{*}$ \\
\hline
\end{tabular}

${ }^{*} \chi^{2}$ test.

†One-way analysis of variance.

$\mathrm{AHI}$, apnoea-hypopnoea index in events/hour of total sleep time; BMI, body mass index. 
alterations, a history of other sleep or cognitive disorders, psychiatric or muscle wasting diseases, patients whose sleep studies revealed a proportion of central apnoeas $>10 \%$ of all events, and those with other comorbidities in advanced stages (chronic obstructive pulmonary disease, cardiac insufficiency and severe arrhythmias).

Information was retrieved from the electronic databases containing the medical records of all patients who underwent a standard PSG between February 2007 and January 2017. A total of 10478 eligible consecutively studied patients were identified. There were 8580 patients corresponding to the period between February 2007 and December 2014 who were used for the construction of the instrument. Another 1898 patients were then recruited from January 2015 to January 2017 whose data were used for tool validation.

Immediately before each PSG, age, sex, weight, height, BMI, neck circumference at the level of the cricoid cartilage, a history of arterial hypertension and blood pressure measurements were collected. Other collected data included the presence of daytime sleepiness, as measured by the ESS, sleep onset insomnia, maintenance insomnia, night awakenings, nonrestorative sleep, sleepwalking, nightmares, leg movements, sweating, heartburn, dry mouth and the Berlin questionnaire.

PSGs were performed during natural nighttime sleep at the patient's usual bedtime. The PSG was performed using the Alice 5 and 6 digital systems (Philips Respironics, Pennsylvania, USA). Standard electroencephalography, electro-oculography, mandible and leg electromyography, nasal and oral airflow, electrocardiography, respiratory effort and oxygen saturation were included. The PSG was manually scored by a certified technician and reviewed by a physician certified in sleep medicine.
Sleep stages and respiratory events were scored according to the recommendations of the American Academy of Sleep Medicine (AASM) Manual for Scoring of Sleep and Associated Events 2007. ${ }^{35} 36$ The clinical diagnosis of OSA was defined by an AHI $\geq 5$ events/hour of sleep, with symptoms of sleep fragmentation and daytime somnolence, according to the AASM. The severity of OSA was determined according to the AHI as follows: mild, 5-14.9; moderate, 15-30; and severe, greater than 30 events/hour of total sleep time. Hypopnoea was defined as a significant decrease in the baseline amplitude of a valid measure of breathing for at least $10 \mathrm{~s}$ during sleep, along with an oxygen desaturation of $\geq 3 \%$ or an arousal. ${ }^{37}$

\section{Statistical analysis}

Data are presented as mean \pm SD for quantitative variables and frequencies (absolute and relative) for qualitative variables. Bivariate analyses were initially conducted and the variables that were associated with OSA were identified. The independent variables included age, sex, weight, height, BMI, neck circumference, arterial hypertension, snoring, sleep apnoea, choking and fatigue. Other independent variables included daytime sleepiness, muscle weakness, insomnia, night awakenings, waking up to go to the bathroom at night, non-restorative sleep, sleepwalking, nightmares, leg movements, sweating, heartburn and mouth dryness. Finally, those variables that showed statistical significance and biological plausibility were included in the construction of the severe OSA prediction model. Cut-off values for continuous independent variables were derived from receiver operating characteristic (ROC) curves. Missing data were completed using multiple imputation procedures prior to statistical analysis.

\section{Table 2 Clinical and anthropometric variables associated with severe OSA (AHI >30 events/hour TST)}

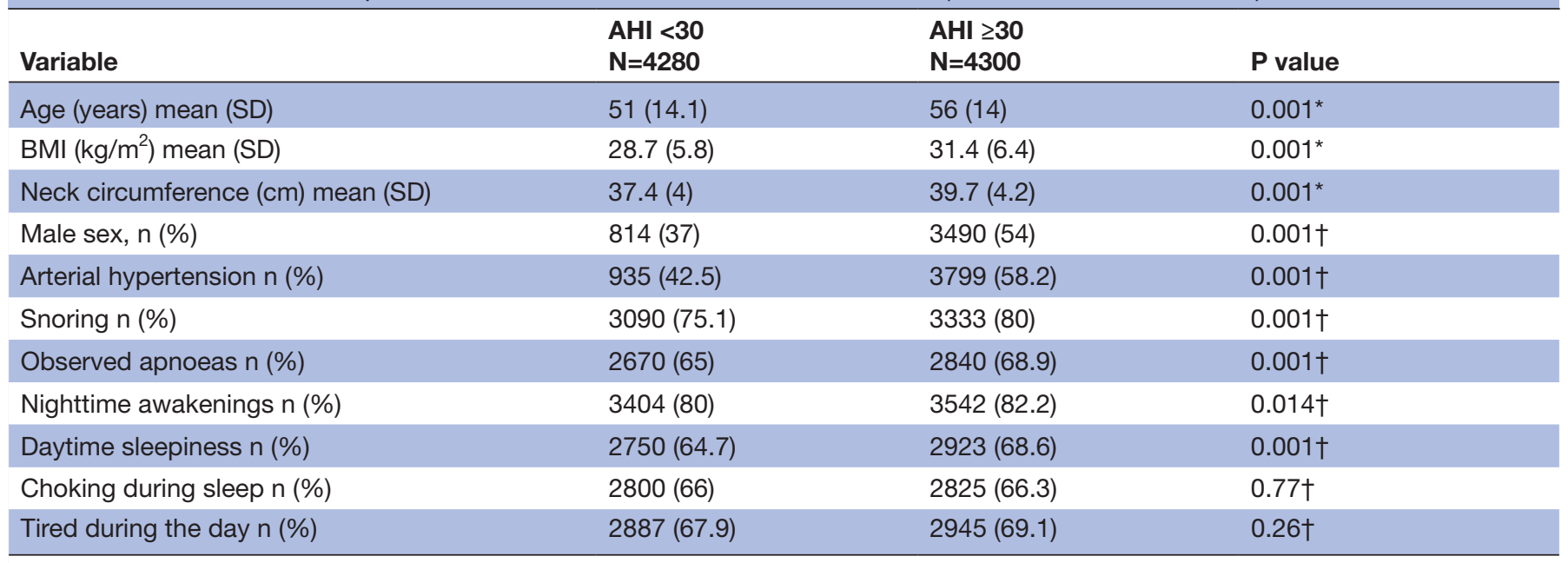

*One-way analysis of variance.

$+\chi^{2}$ test.

AHI, apnoea-hypopnoea index; BMI, body mass index; hour TST, hour of total sleep time; OSA, obstructive sleep apnoea. 


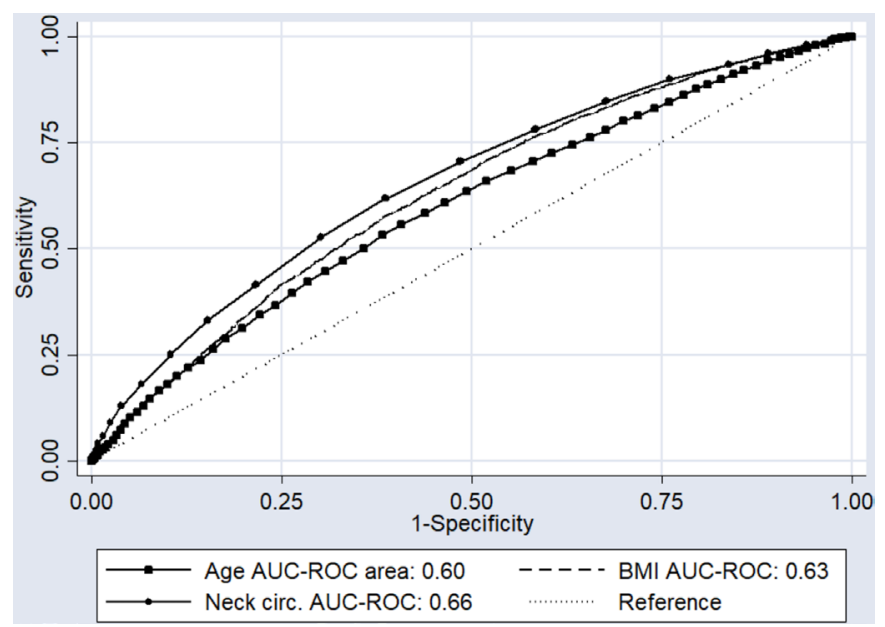

Figure 1 ROC curves for predictor variables in the derivation cohort. AUC-ROC (binomial exact) in the derivation cohort of age: 0.60 (95\% Cl: 0.59 to 0.61$)$; $\mathrm{BMl}$ : 0.63 (95\% Cl: 0.62 to 0.64$)$; and neck circumference: 0.66 (95\% Cl: 0.65 to 0.67). AUC-ROC, area under the receiver operating characteristic curve; BMI body mass index; circ., circumference.

The cohort of patients recruited from 2007 to 2014 served for development of the prediction model. Through logistic regression analyses, associations of the different variables with the crude and adjusted OSA outcomes were quantified. Based on these findings, the construction and fit of the model were explored, while identifying interaction, confusion and collinearity. A two-tailed value of $\mathrm{p}<0.05$ was considered statistically significant. Validation of the instrument to test the goodness of fit and discrimination capacity was performed in a patient population different from that used to develop the model (the cohort recruited from 2015 to 2017). All statistical analyses were performed using the statistical packages SAS V.9.4 and STATA V.14, and Microsoft Office Excel 2016 was used to build the databases.
Patient and public involvement

No patients were involved.

\section{RESULTS}

The data from 10478 patients were included in the study, with 8580 (82\%) serving to develop the model, and the remaining 1898 (18\%) used for validation of the model. The patients identified themselves predominantly as Hispanics. The prevalence of OSA in this high-risk clinical referral population was $94.8 \%$, with $49.2 \%$ having severe OSA. The mean age was $53.5 \pm 14.3$ years, BMI was $30.1 \pm 6.3 \mathrm{~kg} / \mathrm{m}^{2}$, neck circumference was $38.6 \pm 4.2 \mathrm{~cm}$ and $54.5 \%$ had arterial hypertension (table 1). Additionally, as the OSA severity increased, age, BMI, neck circumference, snoring and the prevalence of arterial hypertension also increased (tables 1 and 2). A weak correlation between BMI and neck circumference was observed $(r=0.4)$. No significant differences emerged in ESS and the presence of OSA (ESS: $10.1 \pm 6.0$ ) or absence of OSA (ESS: 10.2 \pm 6.1) $(\mathrm{p}=0.4)$. Variables, including age, BMI and neck circumference, were then dichotomised based on the optimal cut-off point obtained from ROC curves (figure 1), with determination of cut-offs of greatest discrimination carried out according to the Youden index. These cut-off points were $38.9 \mathrm{~cm}$ for neck circumference, $28.5 \mathrm{~kg} / \mathrm{m}^{2}$ for BMI and 54.5 years for age. With these dichotomous variables, we proceeded to construct the various models (table 3 ).

Seven models were generated by the stepwise forward logistic regression method, leading to the selection of the most parsimonious model, with a coefficient of determination of $\mathrm{R}^{2}=0.09$. This model included the following variables: male sex, age $(\geq 55$ for the general predictor model, $>50$ years for the male model and $\geq 55$ for the female model), neck circumference $(\geq 39 \mathrm{~cm}$ for the general predictor model, $>41 \mathrm{~cm}$ for the male model and $\geq 36 \mathrm{~cm}$ for the female

\begin{tabular}{llllll}
\hline \multicolumn{5}{l}{ Table 3 Cut-offpoints with greater discriminatory capacity (Youden index) } & for the variables associated with severe OSA \\
\hline Variable & Population & Cut-off point & Sens. & Spec. & AUC-ROC \\
\hline Neck circumference $(\mathrm{cm})$ & General & 38.9 & 0.62 & 0.61 & 0.62 \\
& Men & 40.8 & 0.60 & 0.60 & 0.60 \\
& Women & 36.2 & 0.58 & 0.61 & 0.59 \\
BMI $\left(\mathrm{kg} / \mathrm{m}^{2}\right)$ & General & 29.4 & 0.58 & 0.61 & 0.60 \\
& Men & 28.1 & 0.62 & 0.59 & 0.61 \\
& Women & 29.8 & 0.63 & 0.59 & 0.61 \\
Age (years) & General & 54.5 & 0.56 & 0.59 & 0.57 \\
& Men & 50.5 & 0.58 & 0.53 & 0.56 \\
& Women & 55.5 & 0.64 & 0.59 & 0.61
\end{tabular}

AUC-ROC, area under the receiver operating characteristic curve; BMI, body mass index; OSA, obstructive sleep apnoea; Sens., sensitivity; Spec., specificity. 
Table 4 General predictive model for severe OSA (most parsimonious)

\begin{tabular}{|c|c|c|c|c|c|c|}
\hline Variables & OR & $95 \% \mathrm{Cl}$ & $P$ value & $\mathbf{R}^{2}$ & Wald test & Score \\
\hline Age ( $\geq 55$ years) & 1.9 & 1.7 to 2.1 & $<0.001$ & & 172 & 2 \\
\hline BMI $(\geq 30)$ & 2.0 & 1.8 to 2.2 & $<0.001$ & & 185 & 2 \\
\hline Arterial hypertension & 1.5 & 1.3 to 1.6 & $<0.001$ & & 61 & 2 \\
\hline
\end{tabular}

Multivariate model by binary logistic regression.

BMI, body mass index; OSA, obstructive sleep apnoea.

model), BMI ( $\geq 30$ for the general predictor model, $>28 \mathrm{~kg} / \mathrm{m}^{2}$ for the male model and $\geq 30$ for the female model) and the presence of arterial hypertension. For each of these variables, the ORs were calculated (tables 4-6). Finally, scores were assigned to each of the variables according to the value of the adjusted ORs (tables 4-6), assigning 2 points for each of the five variables present to obtain a score between 0 and 10 for the general predictor model and between 0 and 8 for the male/female specific models. Such variables were summarised with the acronym BASAN (BMI, Age, Sex, Arterial hypertension and Neck circumference), which is the proposed screening instrument for severe OSA.

Regarding the validation of the BASAN index in terms of discrimination and goodness of fit, an area under the curve (AUC)-ROC of 0.69 (95\% CI: 0.68 to 0.70 ) was obtained in the derivation cohort, and 0.67 (95\% CI: 0.65 to 0.69 ) in the validation cohort (figure 2 ). The fit of the model according to the Hosmer-Lemeshow test was good for all score categories of the scale, with a value of $\chi^{2}=3.87(\mathrm{p}=0.42)$. The cut-off point of the BASAN index (general model) with greater discriminative capacity was $\geq 4$ points, which showed a sensitivity of $82.1 \%$ and specificity of $40.4 \%$ with corresponding positive likelihood ratio 1.4 and negative likelihood ratio 4 to detect severe OSA. In contrast, a BASAN index $\geq 2$ had a sensitivity of $95 \%$ and specificity of $17 \%$ to detect severe OSA in the validation cohort. Additional cut-off points with their corresponding sensitivities/specificities and Likelihood ratios (LRs) may be found in the online supplemental tables S1 and S2. The overall predictive properties of the BASAN index were remarkably similar and stable in both the derivation and validation cohorts.
The predictive model for severe OSA in men aged $\geq 50$ years, neck circumference $\geq 41 \mathrm{~cm}$, BMI $\geq 28 \mathrm{~kg} / \mathrm{m}^{2}$ and arterial hypertension is shown in figure 2 and table 5 . The model for women aged $\geq 55$ years, neck circumference $\geq 36 \mathrm{~cm}, \mathrm{BMI} \geq 30 \mathrm{~kg} / \mathrm{m}^{2}$ and arterial hypertension is shown in figure 2 and table 6 . The scoring methods for men and women were similar, assigning a score of 2 for each positive predictor, for a maximum score of 8 points in both models (tables 5 and 6). In the male model, a score $\geq 2$ had a sensitivity of $93 \%$ and a specificity of $20 \%$ to predict severe OSA, while in the female model, a score $\geq 2$ had a sensitivity of $95 \%$ and a specificity of $17 \%$ to predict severe OSA. Higher scores had better specificities at the expense of sensitivity, as shown in the online supplemental tables S3-S6. The reader can use these tables to select cut-off points that better fit specific aims.

Several cluster analyses were performed as shown in the online supplemental figures S1-S6 with similar discriminant capacity in all figures, except in the cluster of snoring patients where the model showed a higher AUC-ROC of 0.70 (online supplemental figure S6). We also obtained the percentiles for each quantitative predictor variable (age, BMI and neck circumference) for men and women according to the AHI (table 7), which may be used as a reference for a population living at moderate to high altitudes.

\section{DISCUSSION}

In the present study, a screening instrument for the presence of severe OSA was developed and validated in a large cohort of patients living at high altitude and clinically referred for PSG due to a clinical suspicion of OSA. Interestingly, we found five variables that were significantly

Table 5 Predictive model for severe OSA in men (most parsimonious)

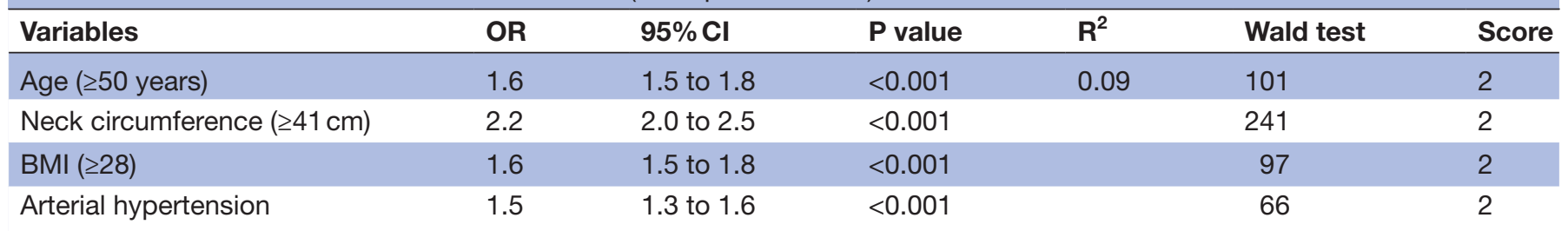

Multivariate model by binary logistic regression.

BMI, body mass index; OSA, obstructive sleep apnoea. 
Table 6 Predictive model for severe OSA in women (most parsimonious)

\begin{tabular}{|c|c|c|c|c|c|c|}
\hline Variables & OR & $95 \% \mathrm{Cl}$ & $P$ value & $\mathbf{R}^{2}$ & Wald test & Score \\
\hline Age ( $\geq 55$ years) & 1.7 & 1.6 to 1.9 & $<0.001$ & 0.09 & 135 & 2 \\
\hline Neck circumference $(\geq 36 \mathrm{~cm})$ & 2.3 & 2.2 to 2.6 & $<0.001$ & & 222 & 2 \\
\hline Arterial hypertension & 1.4 & 1.3 to 1.5 & $<0.001$ & & 55 & 2 \\
\hline
\end{tabular}

Multivariate model by binary logistic regression.

BMI, body mass index; OSA, obstructive sleep apnoea.

related to the presence of severe OSA, namely male sex, age older than 50 years for men and 55 years for women, neck circumference greater than $41 \mathrm{~cm}$ for men and 36 $\mathrm{cm}$ for women, BMI greater than $28 \mathrm{~kg} / \mathrm{m}^{2}$ for men and $30 \mathrm{~kg} / \mathrm{m}^{2}$ for women, and the presence of arterial hypertension. Based on their relatively similar contributions to the risk of suffering from severe OSA, we attributed a similar scoring approach to each of the variables and constructed the BASAN screening instrument. The performance of this tool was obviously designed to screen rather than diagnose severe OSA, as reflected by the very high sensitivity and low specificity. The BASAN index was then validated in a subsequent relatively large cohort of nearly 1900 patients with virtually identical findings.

In our study, we found that patients with mild, moderate and severe OSA had mean BMI values of 28,29 and $31 \mathrm{~kg} / \mathrm{m}^{2}$, respectively, consistent with the AASM guidelines, which recognises the risk of OSA above a BMI of $30 \mathrm{~kg} / \mathrm{m}^{2}$. However, our cut-off values were slightly different from those reported in studies conducted at sea level and are more consistent with our clinical empirical observations among high altitude residents. A similar BMI cut-off was also described in the Berlin questionnaire, and by Takegami and colleagues $^{38}$ in the 4-Variable tool for screening patients with OSA. In contrast, the STOP-Bang scale recognises the risk of OSA starting at a BMI greater than $35 \mathrm{~kg} / \mathrm{m}^{2}$, an age greater than 50 years and a neck circumference greater than $40 \mathrm{~cm} .{ }^{19}$ Such values were different in our study, which found lower cutoff values than the majority of those reported in the literature. Therefore, our values may simply reflect the characteristics of the Hispanic population living at altitudes around $2600 \mathrm{~m}$.a.s.l. This may further reinforce the concept that regional differences around the globe require careful tailoring and validation of any screening instrument to the population of interest, rather than assuming that one size fits all.

The clinical attractiveness of the BASAN index is first and foremost predicated on the fact that it was developed through a fairly parsimonious model, and that the five items retained are easy to measure and readily available in any clinical practice. Thus, the BASAN index should enable primary care clinicians to assign a probability of severe OSA among their patients living at high altitudes, a critically useful feature enabling prioritisation of care to those patients who require a more immediate diagnosis and treatment. However, the derivation and validation of the BASAN tool was conducted in patients with high pretest probability. For a disease like OSA, it is potentially more important that a screening test has a high sensitivity rather than a high specificity. ${ }^{14}$ Nevertheless, this approach is not unanimously endorsed, and an earlier study has shown that the strategy of different cut-off points for any screening instrument may be interesting depending on the specific aim to confirm or exclude OSA. ${ }^{39}$ In addition, in a population with an elevated prevalence of OSA, such as in a sleep laboratory, using a screening instrument that exhibits a high sensitivity, such as the BASAN index, might lead to increases in the false positive rate. While sensitivity and specificity are not altered by the prevalence of the disease, predictive values are largely dependent on disease prevalence in the population of interest. ${ }^{40}{ }^{41} \mathrm{It}$ is therefore possible that exploration of other cut-off values for BASAN that modulate between sensitivity and specificity may be of greater interest in clinical practices or regions in which a lower prevalence of OSA prevails, such as in primary care.

Our large sample size allowed us to include heterogeneous subjects and to address the impact of such heterogeneities in the predictive capacity of the model. Furthermore, we assigned scores to the variables included in the model based on standardised B coefficients and ORs according to the most rigorous validity processes. ${ }^{42}$ The STOP questionnaire included 211 patients who underwent PSG to classify them as high risk and to then define the cut-off points of the variables according to their positive predictive values. These cut-off points were as follows: age $>50$ years, BMI $>35 \mathrm{~kg} / \mathrm{m}^{2}$, neck circumference $>40 \mathrm{~cm}$ and sex; however, by not taking into account the negative predictive values, there are limitations in the discrimination capacity for each variable. ${ }^{1743}$ Subramanian et al developed the neck circumference, airway classification, comorbidities, Epworth scale and snoring (NAMES) scale $^{43}$ by enrolling 659 Hispanic and Caucasian adults living at altitudes close to sea level who were referred to a sleep laboratory due to a clinical suspicion of OSA. In their study, the cut-off points were defined according to the literature and expert 

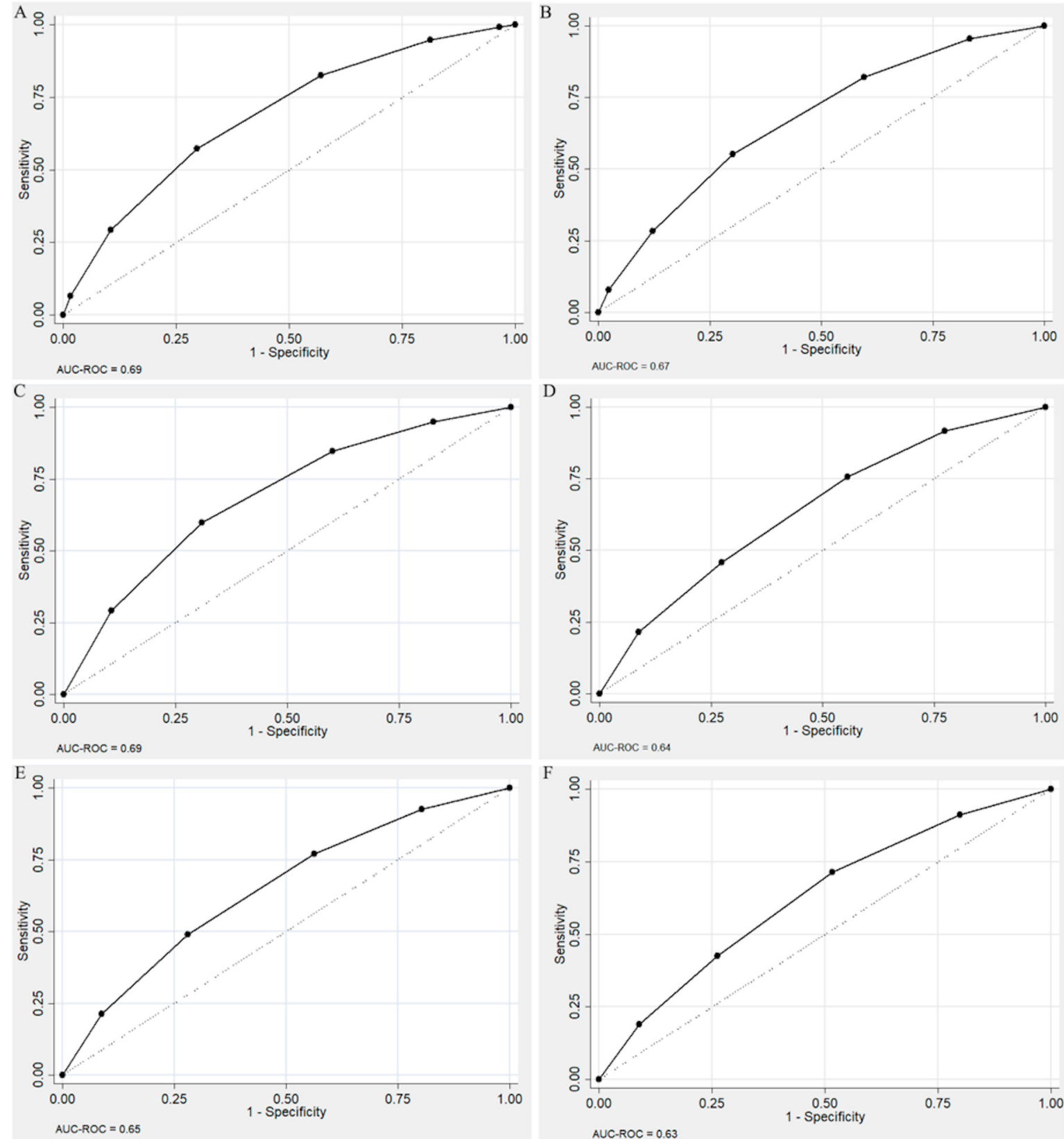

Figure 2 ROC curves of the general, female and male models to predict severe obstructive sleep apnoea in the derivation and validation cohorts. (A) General model in the derivation cohort. (B) General model in the validation cohort. (C) Female model in the derivation cohort. (D) Female model in the validation cohort. (E) Male model in the derivation cohort. (F) Male model in the validation cohort. AUC-ROC markers correspond to model total score (2 points per each predictor positive according to tables 5-7). AUC-ROC (binomial exact) general model in the derivation cohort: 0.69 (95\% Cl: 0.68 to 0.70$)$; general model in the validation cohort: 0.67 ( $95 \% \mathrm{Cl}: 0.65$ to 0.69 ); female model in the derivation cohort: 0.69 (95\% Cl: 0.67 to 0.70$)$; female model in the validation cohort: 0.64 (95\% Cl: 0.61 to 0.68 ); male model in the derivation cohort: 0.65 (95\% Cl: 0.63 to 0.66$)$; and male model in the validation cohort: $0.63(95 \% \mathrm{Cl}: 0.59$ to 0.67$)$. AUC-ROC, area under the receiver operating characteristic curve.

opinions, an approach that may lead to suboptimal selection of cut-off points relative to the test candidate population. The NAMES scale achieved similar performance characteristics to the Berlin questionnaire, ${ }^{1316}$ with AUC-ROCs ranging from 0.64 to 0.66 and sensitivities from $91 \%$ to $99 \%$ (higher than the ESS $)^{44}$ and specificities between $9 \%$ and $27 \%$. The addition of BMI and sex to this tool improved the detection of OSA, concluding that the NAMES scale is an effective and economic screening strategy in patients with moderate to severe OSA. ${ }^{43}$ The methodology used for the development and validation of our BASAN index enabled higher AUC-ROC. There was also an improved balance between sensitivity (82\%) and specificity $(41 \%)$ than with NAMES, as well as those of other instruments developed for OSA detection, including the Berlin, STOP and STOP-Bang questionnaires. $^{44-46}$ 
Open access

Table 7 Percentiles of quantitative predictor variables according to $\mathrm{AHI}$

\begin{tabular}{|c|c|c|c|c|c|c|c|c|}
\hline \multirow[b]{2}{*}{ Variable } & \multicolumn{4}{|c|}{ Women-AHI } & \multicolumn{4}{|c|}{ Men-AHÍ } \\
\hline & $<5$ & $<30$ & $\geq 30$ & $P$ value & $<5$ & $<30$ & $\geq 30$ & $P$ value \\
\hline \multicolumn{9}{|l|}{ Age } \\
\hline Mean & 43.9 & 52.1 & 59.6 & 0.001 & 44.9 & 49.8 & 53.4 & 0.001 \\
\hline SD & 13.4 & 13.87 & 13.1 & & 16.9 & 14.4 & 14.1 & \\
\hline 100th percentile & 87 & 93 & 92 & & 86 & 90 & 89 & \\
\hline 99th percentile & 79 & 83 & 85 & & 85 & 83 & 83 & \\
\hline 95th percentile & 69 & 75 & 80 & & 78 & 74 & 76 & \\
\hline 90th percentile & 63 & 70 & 77 & & 68 & 69 & 72 & \\
\hline 75th percentile & 53 & 62 & 69 & & 56 & 60 & 64 & \\
\hline 50th percentile & 43 & 53 & 60 & & 44 & 50 & 53 & \\
\hline 25th percentile & 34 & 43 & 52 & & 30 & 39 & 42 & \\
\hline 10th percentile & 27 & 33 & 43 & & 22 & 31 & 34 & \\
\hline 5th percentile & 24 & 28 & 36 & & 20 & 27 & 30 & \\
\hline 1st percentile & 19 & 22 & 26 & & 18 & 20 & 25 & \\
\hline 0 percentile & 18 & 18 & 19 & & 18 & 18 & 18 & \\
\hline \multicolumn{9}{|l|}{ BMI $\left(\mathrm{kg} / \mathrm{m}^{2}\right)$} \\
\hline Mean & 27.5 & 29.5 & 32.7 & 0.001 & 26.9 & 27.7 & 30.4 & 0.001 \\
\hline SD & 6.2 & 6.4 & 6.9 & & 4.9 & 4.8 & 5.9 & \\
\hline 100th percentile & 48 & 65 & 70 & & 49 & 59 & 88 & \\
\hline 99th percentile & 46 & 48 & 53 & & 46 & 45 & 50 & \\
\hline 95th percentile & 39 & 41 & 45 & & 35 & 36 & 41 & \\
\hline 90th percentile & 37 & 38 & 42 & & 33 & 33 & 38 & \\
\hline 75th percentile & 31 & 33 & 37 & & 30 & 30 & 33 & \\
\hline 50th percentile & 26 & 28 & 32 & & 26 & 27 & 29 & \\
\hline 25th percentile & 23 & 25 & 28 & & 23 & 25 & 27 & \\
\hline 10th percentile & 21 & 22 & 24 & & 21 & 23 & 24 & \\
\hline 5th percentile & 20 & 21 & 23 & & 21 & 21 & 23 & \\
\hline 1st percentile & 17 & 18 & 20 & & 18 & 19 & 21 & \\
\hline 0 percentile & 15 & 13 & 14 & & 18 & 14 & 17 & \\
\hline \multicolumn{9}{|c|}{ Neck circumference } \\
\hline Mean & 34.8 & 35.7 & 37.3 & 0.001 & 39.2 & 39.9 & 41.6 & 0.001 \\
\hline SD & 3 & 3.4 & 3.6 & & 3.6 & 3.5 & 3.7 & \\
\hline 100th percentile & 43 & 68 & 64 & & 49 & 69 & 69 & \\
\hline 99th percentile & 43 & 45 & 47 & & 49 & 49 & 50 & \\
\hline 95th percentile & 40 & 42 & 43 & & 45 & 46 & 48 & \\
\hline 90th percentile & 39 & 40 & 42 & & 44 & 44 & 46 & \\
\hline 75th percentile & 37 & 38 & 40 & & 41 & 42 & 44 & \\
\hline 50th percentile & 35 & 36 & 37 & & 39 & 40 & 41 & \\
\hline 25th percentile & 33 & 33 & 35 & & 37 & 38 & 39 & \\
\hline 10th percentile & 31 & 32 & 33 & & 35 & 36 & 37 & \\
\hline 5th percentile & 30 & 31 & 32 & & 33 & 35 & 36 & \\
\hline 1st percentile & 29 & 29 & 30 & & 28 & 31 & 33 & \\
\hline 0 percentile & 27 & 26 & 23 & & 27 & 24 & 25 & \\
\hline
\end{tabular}

AHI, apnoea-hypopnoea index. 


\section{Limitations and strengths}

In the bivariate analysis, we did not find an association between ESS scores and OSA. This is consistent with the findings of most previous studies because the ESS was designed to evaluate daytime sleepiness, as it is one of the most common symptoms of OSA, and not to discriminate the severity of OSA. ${ }^{24}{ }^{47-53}$ The frequent use of the ESS in our country to make decisions about the need for a PSG may have affected its a priori discriminatory ability, particularly when considering that our cohort had mean ESS scores of 10. Our study included a low proportion of patients without OSA, a factor that clearly limited our ability to develop a predictive model for mild OSA. Notwithstanding, the population of our study reflects the characteristics of Hispanics living at altitudes around 2600 m.a.s.l. who are usually referred for PSG. Furthermore, the BASAN index should allow for the detection of those patients at higher risk of severe OSA, who would be the priority group for referral to PSG. On the other hand, as with any observational and retrospective study, there is a risk of confounding bias and omission. To circumvent this risk, we adhered to the existing recommendations for the construction of logistic regression models. ${ }^{42}$

\section{CONCLUSION}

The BASAN index showed adequate discrimination and calibration for predicting severe OSA. The greatest utility of the BASAN index is in the selection of symptomatic patients living at high altitudes who are at the highest risk for morbidities and therefore should be a priority for a diagnostic PSG and treatment. Future implementation and validity corroboration of this instrument among primary care settings will be required.

\section{Author affiliations}

${ }^{1}$ School of Medicine, Epidemiology and Biostatistics Department, Universidad de La Sabana, Chia, Colombia

${ }^{2}$ Pulmonary and Sleep Medicine - Grupo de Investigación en Sueño, CAYRE, Bogotá, D.C, Colombia

${ }^{3}$ Internal Medicine, Universidad de La Sabana, Chia, Colombia

${ }^{4}$ Interventional Pulmonology and Research Department, Fundacion Neumologica

Colombiana, Bogotá, D.C, Colombia

${ }^{5}$ Department of Child Health and the Children's Hospital Research Institute,

University of Missouri, Columbia, Missouri, USA

\section{Twitter Luis Fernando Giraldo-Cadavid @luisfgiraldo}

Contributors HO, RL, LFGC and KH had full access to all of the data in the study and take responsibility for the integrity of the data and the accuracy of the data analysis. HO, RL, LFGC, AB, CB, RB, LP, KH and DG contributed substantially to the study design, data analysis and interpretation, and the writing of the manuscript. $\mathrm{HO}$ and LFGC contributed substantially to data statistical analysis.

Funding This study was founded by Universidad de La Sabana, grant: MED-211 2016. DG is supported by National Institutes of Heath grants 1R01HL130984 and R56 HL140548.

Competing interests None declared.

Patient consent for publication Not required.

Ethics approval The Institutional Review Board Investigation Subcommittee of the Universidad de La Sabana, Chía, Colombia, approved this study (Act №. 450 of 9 November 2018). According to resolution number 8430 of 1993, Ministry of Health of Colombia, this study is considered an investigation without risk.
Therefore, national legislation personal data protection is required but not informed consent.The study was approved by the institutional review board of the Ondina Clinic.

Provenance and peer review Not commissioned; externally peer-reviewed.

Data availability statement All data relevant to the study are included in the article or uploaded as supplementary information. Deidentified participant data.

Supplemental material This content has been supplied by the author(s). It has not been vetted by BMJ Publishing Group Limited (BMJ) and may not have been peer-reviewed. Any opinions or recommendations discussed are solely those of the author(s) and are not endorsed by BMJ. BMJ disclaims all liability and responsibility arising from any reliance placed on the content. Where the content includes any translated material, BMJ does not warrant the accuracy and reliability of the translations (including but not limited to local regulations, clinical guidelines, terminology, drug names and drug dosages), and is not responsible for any error and/or omissions arising from translation and adaptation or otherwise.

Open access This is an open access article distributed in accordance with the Creative Commons Attribution Non Commercial (CC BY-NC 4.0) license, which permits others to distribute, remix, adapt, build upon this work non-commercially, and license their derivative works on different terms, provided the original work is properly cited, appropriate credit is given, any changes made indicated, and the use is non-commercial. See: http://creativecommons.org/licenses/by-nc/4.0/.

ORCID iD

Henry Oliveros http://orcid.org/0000-0002-7632-906X

\section{REFERENCES}

1 Benjafield AV, Ayas NT, Eastwood PR, et al. Estimation of the global prevalence and burden of obstructive sleep apnoea: a literaturebased analysis. Lancet Respir Med 2019;7:687-98.

2 Heinzer R, Vat S, Marques-Vidal P, et al. Prevalence of sleepdisordered breathing in the general population: the HypnoLaus study. Lancet Respir Med 2015;3:310-8.

3 Young T, Palta M, Dempsey J, et al. The occurrence of sleepdisordered breathing among middle-aged adults. N Engl J Med 1993;328:1230-5.

4 Apprill M, Weitzenblum E, Krieger J, et al. Frequency and mechanism of daytime pulmonary hypertension in patients with obstructive sleep apnoea syndrome. Cor Vasa 1991;33:42-9.

5 Peker $\mathrm{Y}$, Kraiczi $\mathrm{H}$, Hedner J, et al. An independent association between obstructive sleep apnoea and coronary artery disease. Eur Respir J 1999;14:179-84.

6 Cepeda-Valery B, Acharjee S, Romero-Corral A, et al. Obstructive sleep apnea and acute coronary syndromes: etiology, risk, and management. Curr Cardiol Rep 2014;16:535.

7 Arzt M, Young T, Peppard PE, et al. Dissociation of obstructive sleep apnea from hypersomnolence and obesity in patients with stroke. Stroke 2010;41:e129-34.

8 Dyken ME, Im KB. Obstructive sleep apnea and stroke. Chest 2009;136:1668-77.

9 Gami AS, Olson EJ, Shen WK, et al. Obstructive sleep apnea and the risk of sudden cardiac death: a longitudinal study of 10,701 adults. $J$ Am Coll Cardiol 2013;62:610-6.

10 Wong HS, Williams AJ, Mok Y. The relationship between pulmonary hypertension and obstructive sleep apnea. Curr Opin Pulm Med 2017;23:517-21.

11 Ambrosetti M, Lucioni A, Ageno W, et al. Is venous thromboembolism more frequent in patients with obstructive sleep apnea syndrome? $J$ Thromb Haemost 2004;2:1858-60.

12 Baldi I, Gulati A, Lorenzoni G, et al. Public health implications of obstructive sleep apnea burden. Indian J Pediatr 2014;81:55-62.

13 Abrishami A, Khajehdehi A, Chung F. A systematic review of screening questionnaires for obstructive sleep apnea. Can $J$ Anaesth 2010;57:423-38.

14 Alam A, Chengappa KNR, Ghinassi F. Screening for obstructive sleep apnea among individuals with severe mental illness at a primary care clinic. Gen Hosp Psychiatry 2012;34:660-4.

15 Johns MW. Reliability and factor analysis of the Epworth Sleepiness scale. Sleep 1992;15:376-81.

16 Netzer NC, Stoohs RA, Netzer CM, et al. Using the Berlin questionnaire to identify patients at risk for the sleep apnea syndrome. Ann Intern Med 1999;131:485-91.

17 Chung F, Yegneswaran B, Liao P. Stop questionnaire: a tool to screen patients for obstructive sleep apnea. Anesthesiology 2008;108:812-21. 
18 Ong TH, Raudha S, Fook-Chong S, et al. Simplifying Stop-Bang: use of a simple questionnaire to screen for OSA in an Asian population. Sleep Breath 2010;14:371-6.

19 Guichard K, Marti-Soler H, Micoulaud-Franchi J-A, et al. The NoSAS score: a new and simple screening tool for obstructive sleep apnea syndrome in depressive disorder. J Affect Disord 2018;227:136-40.

20 Marti-Soler H, Hirotsu C, Marques-Vidal P, et al. The NoSAS score for screening of sleep-disordered breathing: a derivation and validation study. Lancet Respir Med 2016;4:742-8.

21 Duarte RLM, Rabahi MF, Magalhães-da-Silveira FJ, et al. Simplifying the screening of obstructive sleep apnea with a 2-Item model, NoApnea: a cross-sectional study. J Clin Sleep Med 2018;14:1097-107.

22 Duarte RLM, Mello FCQ, Magalhães-da-Silveira FJ, et al. Comparative performance of screening instruments for obstructive sleep apnea in morbidly obese patients referred to a sleep laboratory: a prospective cross-sectional study. Sleep Breath 2019;23:1123-32.

23 Duarte RLM, Magalhães-da-Silveira FJ, Oliveira-E-Sá TS, et al. Predicting obstructive sleep apnea in patients with insomnia: a comparative study with four screening instruments. Lung 2019;197:451-8

24 Johns MW. Daytime sleepiness, snoring, and obstructive sleep apnea. The Epworth Sleepiness scale. Chest 1993;103:30-6.

25 Johns MW. A new method for measuring daytime sleepiness: the Epworth Sleepiness scale. Sleep 1991;14:540-5.

26 Myers KA, Mrkobrada M, Simel DL. Does this patient have obstructive sleep apnea?: the rational clinical examination systematic review. JAMA 2013;310:731-41.

27 Romeo R, Vita A, Testolin R, et al. Mapping the vulnerabilitiy of mountain peoples to food insecurity. Rome: FAO, 2015.

28 West JB. The physiologic basis of high-altitude diseases. Ann Intern Med 2004;141:789-800.

29 Bloch KE, Latshang TD, Turk AJ, et al. Nocturnal periodic breathing during acclimatization at very high altitude at Mount Muztagh Ata (7,546 M). Am J Respir Crit Care Med 2010;182:562-8.

30 Nussbaumer-Ochsner Y, Ursprung J, Siebenmann C, et al. Effect of short-term acclimatization to high altitude on sleep and nocturna breathing. Sleep 2012;35:419-23.

31 Lombardi C, Meriggi P, Agostoni P, et al. High-altitude hypoxia and periodic breathing during sleep: gender-related differences. J Sleep Res 2013;22:322-30.

32 Ainslie PN, Lucas SJE, Burgess KR. Breathing and sleep at high altitude. Respir Physiol Neurobiol 2013;188:233-56.

33 Frisancho AR. Developmental functional adaptation to high altitude: review. Am J Hum Biol 2013;25:151-68.

34 Iber C, Ancoli-Israel S, Chesson AL, et al. The AASM manual for the scoring of sleep and associated events: rules, terminology and technical specifications. 1st ed. Westchester, IL: American Academy of Sleep Medicine, 2007.

35 Berry RB, Budhiraja R, Gottlieb DJ, et al. Rules for scoring respiratory events in sleep: update of the 2007 AASM manual for the scoring of sleep and associated events. deliberations of the sleep apnea definitions Task force of the American Academy of sleep medicine. $J$ Clin Sleep Med 2012;8:597-619.

36 Anon. Sleep-Related breathing disorders in adults: recommendations for syndrome definition and measurement techniques in clinical research. The report of an American Academy of sleep medicine Task force. Sleep 1999;22:667-89.

37 Takegami M, Hayashino Y, Chin K, et al. Simple four-variable screening tool for identification of patients with sleep-disordered breathing. Sleep 2009;32:939-48.

38 Cowan DC, Allardice G, Macfarlane D, et al. Predicting sleep disordered breathing in outpatients with suspected OSA. BMJ Open 2014;4:e004519.

39 Youden WJ. Index for rating diagnostic tests. Cancer 1950;3:32-5.

40 Steyerberg EW, Vickers AJ, Cook NR, et al. Assessing the performance of prediction models: a framework for traditional and novel measures. Epidemiology 2010;21:128-38.

41 American Society of Anesthesiologists Task Force on Perioperative Management of patients with obstructive sleep apnea. Practice guidelines for the perioperative management of patients with obstructive sleep apnea: an updated report by the American Society of Anesthesiologists Task force on perioperative management of patients with obstructive sleep apnea. Anesthesiology 2014;120:268-86.

42 Hosmer DW, Lemeshow S, Sturdivant RX. The Multiple Logistic Regression Model. In: Hosmer DW, Lemeshow S, Sturdivant RX, eds. Applied logistic regression. 3rd ed. New York, NY: John Wiley \& Sons, Inc, 2013: 35-48.

43 Subramanian S, Hesselbacher SE, Aguilar R, et al. The names assessment: a novel combined-modality screening tool for obstructive sleep apnea. Sleep and Breathing 2011;15:819-26.

44 Pataka A, Daskalopoulou E, Kalamaras G, et al. Evaluation of five different questionnaires for assessing sleep apnea syndrome in a sleep clinic. Sleep Med 2014;15:776-81.

45 Silva GE, Vana KD, Goodwin JL, et al. Identification of patients with sleep disordered breathing: comparing the four-variable screening tool, stop, Stop-Bang, and Epworth sleepiness scales. J Clin Sleep Med 2011;7:467-72

46 Ramachandran SK, Josephs LA. A meta-analysis of clinical screening tests for obstructive sleep apnea. Anesthesiology 2009;110:928-39.

47 Uribe Echevarría EM, Alvarez D, Giobellina R, et al. [Epworth drowsiness scale value in obstructive sleep apnea syndrome] Medicina 2000;60:902-6.

48 Vignatelli L, Plazzi G, Barbato A, et al. Italian version of the Epworth Sleepiness scale: external validity. Neurol Sci 2003;23:295-300.

49 Nguyen ATD, Baltzan MA, Small D, et al. Clinical reproducibility of the Epworth Sleepiness scale. J Clin Sleep Med 2006;2:170-4.

50 Tachibana N, Taniguchi M. Why do we continue to use Epworth Sleepiness scale? Sleep Med 2007;8:541-2.

51 Beiske KK, Kjelsberg FN, Ruud EA, et al. Reliability and validity of a Norwegian version of the Epworth Sleepiness scale. Sleep Breath 2009;13:65-72.

52 Bausmer U, Gouveris H, Selivanova O, et al. Correlation of the Epworth Sleepiness scale with respiratory sleep parameters in patients with sleep-related breathing disorders and upper airway pathology. Eur Arch Otorhinolaryngol 2010;267:1645-8.

53 Luo J, Huang R, Zhong X, et al. Stop-Bang questionnaire is superior to Epworth sleepiness scales, Berlin questionnaire, and stop questionnaire in screening obstructive sleep apnea hypopnea syndrome patients. Chin Med J 2014;127:3065-70. 